\title{
Apresentação Educação e Envelhecimento
}

\author{
Johannes Doll' \\ Anne Carolina Ramos" \\ Caroline Stumpf Buaes ${ }^{\text {III }}$
}

'Universidade Federal do Rio Grande do Sul (UFRGS), Porto Alegre/RS - Brasil "University of Luxembourg (UNI.LU) - Luxemburgo '"Faculdade Meridional (IMED), Passo Fundo/RS-Brasil

O Brasil encontra-se em uma fase de mudança da estrutura etária da sua população. Um número cada vez maior de idosos e um número cada vez mais enxuto de crianças e adolescentes tem feito com que, pela primeira vez na história recente, a maior parcela da população brasileira seja predominantemente adulta e em idade ativa. Sob o ponto de vista demográfico, o envelhecimento populacional é resultado de dois fatores principais: o primeiro é a forte diminuição da taxa de fecundidade, que caiu de 6,2 filhos por mulher em 1960 para 1,8 filhos em 2012; o segundo é a diminuição da mortalidade infantil, que passou de $121 \%$ em 1960 para 15,7\% em 2012. Tais fatores foram impulsionados por mudanças no campo social, educacional, cultural e da saúde, como a descoberta dos antibióticos, a criação das unidades de terapia intensiva e das vacinas, na metade do século passado, e as mudanças no estilo de vida, nos anos 1960. Com isso, a população brasileira envelheceu rapidamente nos últimos 50 anos, e o grupo das pessoas idosas ${ }^{1}$ aumentou de 4,7\% (1960) para 12,6\% (2012). Este processo está levando a uma profunda reestruturação da população do País: o cenário em que as crianças e jovens constituem o maior grupo populacional da pirâmide etária brasileira se reverterá em bem pouco tempo. Após 2030, o grupo dos idosos será maior que o grupo de crianças com até 14 anos e, em 2055, haverá mais idosos do que crianças e jovens com até 29 anos de idade.

Educação \& Realidade, Porto Alegre, v. 40, n. 1, p. 9-15, jan./mar. 2015.

Disponível em: <http://www.ufrgs.br/edu_realidade> 
Apresentação da Seção Temática - Educação e Envelhecimento

Em 2060, mais do que um terço da população brasileira será constituído por pessoas com 60 anos ou mais $(33,7 \%)^{2}$. Nesse contexto de mudanças, a população idosa também se diversifica, alterando a composição etária do próprio grupo: hoje é cada vez maior o número de pessoas que alcança uma idade avançada, e muito avançada, inclusive passando dos 100 anos.

Por um lado, podemos dizer que o aumento da longevidade representa uma conquista do campo social e da saúde. Por outro, apresenta-se como um desafio às demandas sociais e econômicas, sobretudo nos países em desenvolvimento, como é o caso do Brasil (Berquó, 1996). É pautada nessas mudanças que a Gerontologia vai encontrar solo fértil para se expandir, constituindo-se, a partir da segunda metade do século XX, como uma área de estudo multi e interdisciplinar. As primeiras pesquisas gerontológicas surgiram nos campos disciplinares da Psicologia, da Medicina e da Biologia, que colocaram sob relevo questões relativas à saúde, às relações sociais e às capacidades cognitivas dos idosos. A intersecção entre a Educação e a Gerontologia vai aparecer apenas em um segundo momento, quando, nos anos 1970, surgem as primeiras propostas científicas que abordam as relações entre esses dois campos de estudo. Enquanto as primeiras revistas gerontológicas e geriátricas surgiram no contexto norte-americano, ainda nos anos 1940, a primeira revista especializada na relação entre a Gerontologia e a Educação - a revista Educational Gerontology - surgirá apenas em 1976. Nessa ocasião, David A. Peterson, professor da Universidade de Nebraska, publicou um artigo no qual ele estruturou o campo da Gerontologia Educacional da seguinte maneira:

Gerontologia Educacional é o estudo e a prática de ações educacionais para ou sobre a velhice e indivíduos idosos. É possível observar três diferentes, mas relacionados aspectos: (1) atividades educacionais voltadas para pessoas de meia-idade ou idosos; (2) atividades educacionais para um público geral ou específico sobre envelhecimento e pessoas idosas; e (3) preparação educacional para pessoas que trabalham ou pretendem trabalhar com pessoas idosas como profissionais ou de forma profissional (Peterson 1976, p. 62 [tradução dos autores]).

É importante salientar que muitas práticas educativas com idosos já vinham sendo desenvolvidas mesmo antes dessa época. No Brasil, o primeiro trabalho com pessoas idosas foi iniciado pelo SESC/SP ainda nos anos 1960. Na França, contabilizavam-se, no início dos anos 1970, mais de 2000 grupos de idosos ativos. Todavia, essas práticas estavam voltadas mais para atividades de sociabilidade, promovendo a ocupação do tempo livre dos jovens aposentados, do que propostas efetivamente educacionais (Doll, 2008). Para Kolland (2005), esses trabalhos eram marcados por sua característica caritativa-custodial. Pautadas em uma perspectiva assistencialista, essas atividades procuravam oferecer 
aos idosos momentos de entretenimento e diversão, nos quais eles pudessem desenvolver novas formas de contato social. Com o surgimento da Gerontologia Educacional, elementos mais explícitos da ação educativa passaram a integrar as atividades dirigidas aos idosos, fazendo surgir, por exemplo, o movimento das universidades e das escolas abertas à terceira idade.

O tripé sugerido por Peterson nos anos 1970 engloba os diferentes campos de atuação da Educação Gerontológica, sendo uma importante referência até os dias atuais. Contudo, boa parte dos esforços e debates dessa área continuam voltados principalmente às atividades oferecidas à população idosa em grupos de convivência, universidades abertas e instituições de formação continuada. A formação da população em geral sobre o processo de envelhecimento e a preparação dos profissionais que trabalham com idosos foram aspectos muito menos focados no campo da Educação Gerontológica. Todavia, eles são pontos cruciais: por um lado, a formação gerontológica dos profissionais reflete-se diretamente nas ações de atenção, cuidado e educação desse segmento etário; por outro, o envelhecimento é de interesse de todas as faixas etárias, uma vez que esse processo ocorre ao longo de toda a vida, e posto que, em detrimento da maior longevidade, a temática da convivência entre gerações tem entrado cada vez mais em pauta.

Em vista disso, o ensino do envelhecimento nos currículos escolares e nos cursos de graduação e pós-graduação é um aspecto importante da Gerontologia Educacional, que foi inclusive reconhecido no Capítulo V do Estatuto do Idoso:

Nos currículos mínimos dos diversos níveis de ensino formal serão inseridos conteúdos voltados ao processo de envelhecimento, ao respeito e à valorização do idoso, de forma a eliminar o preconceito e a produzir conhecimento sobre a matéria (Brasil, 2004, Estatuto do Idoso, Cap. V, art. 22, s. p.).

É importante lembrar que a questão da pedagogia também está relacionada a discussões culturais. Hoje é possível pensar em uma gama de lugares de aprendizagem, tais como a mídia, a cultura popular, o cinema, a publicidade, as comunicações de massa e as organizações políticas e religiosas (Giroux, 1995). Essas esferas produzem imagens e saberes sobre a velhice que operam como dispositivos pedagógicos (Fischer, 1997), subjetivando os sujeitos e produzindo modos de identificação e compreensão de si e do mundo. As imagens orientam expectativas, valores, percepções e comportamentos, produzindo saberes e identidades por meio dos discursos que elas colocam em circulação. $\mathrm{O}$ trabalho educativo pode desconstruir o estereótipo da velhice como algo necessariamente vinculado à fragilidade, à pobreza e à vulnerabilidade, produzindo novas imagens e novos saberes em relação aos velhos. Atualmente, as identidades de gênero, sexualidade e etnia são

Educação \& Realidade, Porto Alegre, v. 40, n. 1, p. 9-15, jan./mar. 2015.

Disponível em: <http://www.ufrgs.br/edu_realidade> 
Apresentação da Seção Temática - Educação e Envelhecimento

temas centrais no campo da Educação. Em uma sociedade em rápido envelhecimento, onde até cinco gerações podem conviver numa mesma família, a constituição das identidades geracionais são problematizações imprescindíveis, que precisam entrar na pauta do debate educacional.

No que se refere às atividades voltadas diretamente para o público idoso, a intencionalidade e os objetivos de tais propostas podem ser amplamente diversificadas. Universidades abertas para a terceira idade, grupos de convivência, Educação de Jovens e Adultos (que no Brasil recebe um grande número de idosos), treinamento de atletas idosos, curso de informática para adultos maduros, entre outros, refletem a própria heterogeneidade desse grupo, que possui interesses educacionais muitas vezes diversificados. Além disso, trocas intergeracionais, contatos familiares, experiências de vida em instituições de longa permanência, relações de amizade entre idosos e entre diferentes grupos geracionais constituem-se como espaços de ensino e de aprendizagem nos cotidianos da própria vida. Como podemos ver, a intersecção entre a Educação e a Gerontologia ocorre em um vasto contexto de experiências e interesses.

E é justamente alguns aspectos desse vasto campo que a presente Seção Temática - Educação e Envelhecimento - pretende mostrar. Este dossiê tem como propósito trazer para as problematizações educacionais atuais questões relativas ao envelhecimento, promovendo um diálogo entre a Gerontologia e a Educação. Os textos selecionados são multidisciplinares e falam do velho, da velhice, do envelhecimento e do profissional que trabalha nesse campo, a partir de diferentes perspectivas e problemáticas.

Seguindo a proposta de Peterson (1976), os artigos foram organizados em três diferentes grupos. O primeiro está voltado à formação de pessoas idosas, buscando compreender os desafios, os impactos e as possibilidades educativas desse segmento.

No artigo A Formação na Maturidade como Apropriação da Própria História de Vida, Insa Fooken discute como as histórias de vida dos indivíduos podem ser valorizadas como expressão de educação na velhice. Essas histórias são, ao mesmo tempo, individuais e coletivas, na medida em que os indivíduos são perpassados por eventos geracionais que podem deixar profundas marcas em suas biografias. Tomando como base o contexto alemão, a autora analisa as chances, os riscos e os impactos vividos por idosos em suas infâncias durante a Segunda Guerra Mundial e as marcas transgeracionais deixadas pelas guerras, perseguições e extermínios.

Em uma linha análoga, Carolina Silva Sousa e Francisco P. Rodríguez Miranda, no artigo Envelhecimento e Educação para Resiliência no Idoso, discutem como a educação pode operar no processo de resiliência dos idosos, implementando e consolidando capacidades intrínsecas 
ao sujeito e contribuindo para a superação de dificuldades inerentes ao ato educativo. Partindo do pressuposto de que a educação é um processo contínuo, os autores indagam sobre os modos de enfrentamento dos idosos e sobre como eles podem estimular capacidades latentes e acionar mecanismos de superação e de resolução de situações adversas vividas em seus cotidianos.

Uma discussão sobre as formas como pessoas no seu processo de envelhecimento lidam com desafios específicos dessa faixa etária oferece o artigo O Desafio de Aposentar-se no Mundo Contemporâneo, de Daniele dos Santos Fontoura, Johannes Doll e Saulo Neves de Oliveira. A partir de teorias clássicas da Gerontologia, o trabalho analisa as falas de 74 pessoas entre 45 e 76 anos, evidenciando a heterogeneidade dos modos de enfrentamento do evento da aposentadoria.

As atividades educacionais voltadas aos idosos não se fazem sem a reflexão dos métodos pedagógicos utilizados e da formação profissional das pessoas envolvidas, assunto discutido no segundo grupo de artigos que compõe este dossiê.

Em Metodologias e Estratégias Pedagógicas utilizadas por Educadores de uma Universidade Aberta à Terceira Idade, Meire Cachioni, Tiago Nascimento Ordonez, Samila Sathler Tavares Batistoni e Thaís Bento Lima-Silva, ao observarem espaços de aprendizagem voltados a idosos em uma Universidade Aberta, evidenciaram três modelos pedagógicos: pedagogia problematizadora, estratégias cognitivas e pedagogia da transmissão. Neste artigo, os autores discutem esses modelos e apontam alguns desafios enfrentados na educação de idosos, quer para o idoso-aluno, quer para os educadores envolvidos nesse processo.

No artigo Educação Financeira com Idosos em um Contexto Popular, a autora Caroline Stumpf Buaes propõe possibilidades de intervenções educativas para esse segmento da população. Partindo das experiências de consumo e de contrato de crédito consignado por mulheres da classe popular, a autora discute como a apropriação de informações, de conceitos e de sentidos negociados coletivamente em um curso de formação podem oportunizar que o sujeito pense mais criticamente sobre a sua realidade, desenvolvendo o seu protagonismo e a sua autonomia frente ao consumo e ao superendividamento.

Educação, estratégias pedagógicas e formação docente também é o tema central do artigo de Leticia Rocha Machado e Patricia Alejandra Behar. Em Educação à Distância e Cybersêniors: um foco nas estratégias pedagógicas, as autoras discutem os impasses e a necessidade da inserção de aspectos gerontoeducacionais na formação dos profissionais, de modo que cybersêniors possam ser efetivamente incluídos em programas de Educação à Distância.

Contribuindo para a discussão de formação de profissionais da educação, Enrique Fernández Lópiz debate, em Sobre la Formación del Docente-Facilitador de Personas Mayores, estratégias de ensino voltadas

Educação \& Realidade, Porto Alegre, v. 40, n. 1, p. 9-15, jan./mar. 2015.

Disponível em: <http://www.ufrgs.br/edu_realidade> 
Apresentação da Seção Temática - Educação e Envelhecimento

à formação de professores que trabalham com pessoas idosas. Partindo de discussões do campo da Psicogerontologia e da Psicologia Dinâmica, o autor propõe um modelo educativo participativo, no qual o docentefacilitador pode promover a autonomia do aluno-maior.

Um terceiro e último grupo de artigos busca discutir a formação das pessoas em geral sobre o processo de envelhecimento. Esses artigos trazem para a discussão aspectos mais voltados para uma pedagogia cultural sobre o idoso, enfocando aspectos escolares e intergeracionais.

No primeiro artigo deste bloco, Leni Vieira Dornelles analisa a percepção das crianças sobre a velhice a partir da brincadeira com bonecos-velhos. Preocupada com as relações intergeracionais e com aquilo que as crianças têm aprendido e sabem sobre a velhice, a autora discute, em Bonecos com Corpos-Velhos: o que dizem as crianças sobre envelhecimento, o modo como os bonecos-velhos subjetivam as brincadeiras infantis e como as crianças agem frente ao corpo envelhecido de seus brinquedos.

Também no campo das relações intergeracionais, Anne Carolina Ramos discute, em Os Avós na Literatura Infantil: perspectivas gerontológicas e educacionais, as imagens de velhice e avosidade que têm sido ensinadas às crianças nos livros de literatura infantil. Partindo do pressuposto de que os livros infantis operam como uma pedagogia cultural, a autora analisa como os avós aparecem nessas histórias, assim como as relações entre identidades de gênero e geração. São livros utilizados tanto em contextos familiares como escolares, por crianças, parentes e professores.

Como se pode ver, o diálogo entre Educação e Gerontologia abre um leque enorme de temas relevantes. Trata-se, especialmente para a Educação, de um campo a ser constituído e aprofundado. Ao mesmo tempo em que o idoso é ainda novo na Educação, o envelhecimento populacional e as mudanças rápidas do mundo contemporâneo tornam o avanço deste campo de estudo cada vez mais necessário.

\section{Notas}

1 Segundo o Estatuto do Idoso (Lei 10.741/2003), as pessoas com 60 anos ou mais são consideradas idosas no Brasil. Esta classificação segue a orientação da 2a Assembleia Mundial sobre Envelhecimento em Madrid, 2002, onde, em países em desenvolvimento, deve-se considerar idosa a pessoa com 60 anos ou mais. Nos países desenvolvidos o marco é os 65 anos.

2 Dados e projeções do Instituto Brasileiro de Geografia e Estatística IBGE (IBGE, 2013).

\section{Referências}

BERQUÓ, Elza. Algumas Considerações Demográficas sobre o Envelhecimento da População no Brasil. In: I SEMINÁRIO INTERNACIONAL ENVELHECIMEN- 
TO POPULACIONAL: UMA AGENDA PARA O FINAL DO SÉCULO, 1996, Brasília. Anais... Brasília: Ministério da Previdência e Assistência Social, 1996. P. 16-34.

BRASIL. Lei Federal 10.741, de $1^{\circ}$ de outubro de 2003. Estatuto do Idoso. Brasília: Congresso Nacional, 2004

DOLL, Johannes. Educação e Envelhecimento - fundamentos e perspectivas. A Terceira Idade, SESC São Paulo, v. 19, p. 7-26, 2008.

FISCHER, Rosa Maria Bueno. O Estatuto Pedagógico da Mídia. Revista Educação e Realidade, Porto Alegre, Universidade Federal do Rio Grande do Sul, v. 22, n. 2, p. 59-80, jul./dez. 1997.

GIROUX, Henry A. Praticando Estudos Culturais nas Faculdades de Educação. In: SILVA, Tomaz Tadeu da (Org.). Alienígenas na Sala de Aula. Petrópolis: Vozes, 1995. P. 85-103.

IBGE. Instituto Brasileiro de Geografia e Estatística. Síntese de Indicadores Sociais: uma análise das condições de vida da população brasileira. Estudos e Pesquisas Informação Demográfica e Socioeconômica, Rio de Janeiro, n. 32, 2013. KOLLAND, Franz. Bildungschancen für ältere Menschen. Ansprüche an ein gelungenes Leben. Wien: Lit, 2005.

PETERSON, David A. Educational Gerontology: the state of the art. Educational Gerontology: an international quarterly, Washington, DC : Hemisphere, v. 1, p. 61-73, 1976.

Johannes Doll é pedagogo, teólogo, gerontólogo. Possui mestrado em Educação pela Universidade Federal do Rio Grande do Sul/UFRGS e doutorado em Educação pela Universitat Koblenz Landau. Atua como docente da graduação e pós-graduação em Educação na UFRGS. Tem experiência na área de Educação, com ênfase em Educação, atuando principalmente nos seguintes temas: envelhecimento, educação, gerontologia, trabalhadores mais velhos e informática.

E-mail: johannes.doll@ufrgs.br

Anne Carolina Ramos é doutora em Educação pela Universidade Federal do Rio Grande do Sul (Brasil) e pela Universidade de Siegen (Alemanha). Seu foco de estudo está voltado para as relações intergeracionais, desenvolvendo pesquisas que buscam compreender as interfaces entre infância, velhice, família e educação. É pesquisadora associada do Institute for Research and Innovation in Social Work, Social Pedagogy and Social Welfare (IRISS)/Integrative Research Unit on Social and Individual Development (INSIDE) da Universidade do Luxemburgo.

E-mail: annecarolina.ramos@uni.lu

Caroline Stumpf Buaes é psicóloga pela Universidade de Passo Fundo. Possui mestrado e doutorado em Educação pela Universidade Federal do Rio Grande do Sul. Atualmente, é professora da Escola de Psicologia da Faculdade Meridional. Em suas pesquisas desenvolve temas relacionados ao consumo e endividamento a partir da interface entre Psicologia, Educação e Envelhecimento.

E-mail: carolinebuaes@gmail.com

Educação \& Realidade, Porto Alegre, v. 40, n. 1, p. 9-15, jan./mar. 2015.

Disponível em: <http://www.ufrgs.br/edu_realidade> 